Research Article

\title{
Monitoring LST-NDVI Relationship Using Premonsoon Landsat Datasets
}

\author{
Subhanil Guha (D), Himanshu Govil, and Prabhat Diwan \\ Department of Applied Geology, National Institute of Technology Raipur, Raipur, India \\ Correspondence should be addressed to Subhanil Guha; subhanilguha@gmail.com
}

Received 23 December 2019; Revised 5 February 2020; Accepted 7 February 2020; Published 9 June 2020

Academic Editor: Haydee Salmun

Copyright (C) 2020 Subhanil Guha et al. This is an open access article distributed under the Creative Commons Attribution License, which permits unrestricted use, distribution, and reproduction in any medium, provided the original work is properly cited.

\begin{abstract}
The present study monitors the interrelationship of land surface temperature (LST) with normalized difference vegetation index (NDVI) in Raipur City of India using premonsoon Landsat satellite sensor for the season of 2002, 2006, 2010, 2014, and 2018. The results describe that the mean LST of Raipur City is gradually increased with time. The value of mean NDVI is higher in the area below mean LST compared to the area above mean LST. The value of mean NDVI is also higher in Landsat 8 data than Landsat 5 and Landsat 7 data. A strong negative LST-NDVI correlation is observed throughout the period. The correlation coefficient is higher in the area above mean LST and lower in the area below mean LST. The value of the correlation coefficient is decreased with time. The mixed urban landscape of the city is closely related to the changes of LST-NDVI relationship. These results provide systematic planning of the urban environment.
\end{abstract}

\section{Introduction}

Thermal infrared (TIR) bands of satellite images often regulate the biogeochemical actions of the Earth surface features [1-4]. Land surface temperature (LST) determination from TIR bands is very important as it depends on the land surface material and varies from time to time [5]. Fast urbanization rapidly changes the characteristics of the surface components [6]. Natural vegetation is one of the most significant features that control the variation of LST distribution [7]. The most commonly used vegetation index is normalized difference vegetation index (NDVI) which is significantly applied in the computation of LST [8-11]. There are so many factors like climate, types of vegetation, land use, urbanization, etc., that influence the LST-NDVI correlation [12-14].

A number of research scholars recently attempted to build the LST-NDVI correlation [12, 15-17]. Some previous attempts were spatiotemporal in nature and were mainly conducted on the big cities like Tokyo, Shanghai, Chongqing, Shijiazhuang, Rome, Shiraz, Melbourne, Bangkok, Monte Hermoso, Beijing, Islamabad [18-27], etc.
But, the discussion based on the LST-NDVI correlation in an Indian city in premonsoon season was rare.

The surface configurations naturally control the spatial and temporal resolution of any satellite sensor [28]. Generally, LST builds an inverse relationship with vegetation [29]. NDVI acts as a determining factor of LST [30], and some studies used the LST-NDVI correlation to evaluate the distributional pattern of LST [31-36]. A lot of recent studies assess the LST-NDVI correlation in multidimensional approach $[2,32,37-48]$.

Many recent research works conducted on the Indian context describe the LST-NDVI correlation [49-54]. To discuss the spatial-temporal variation of LST-NDVI correlation in the premonsoon season, Raipur, a smart and rapidly growing Indian city, was selected. The study reflects the following specific objectives:

(1) Describe the spatiotemporal distribution of LST and NDVI in the premonsoon months.

(2) Analyze the LST-NDVI correlation in the premonsoon months. 


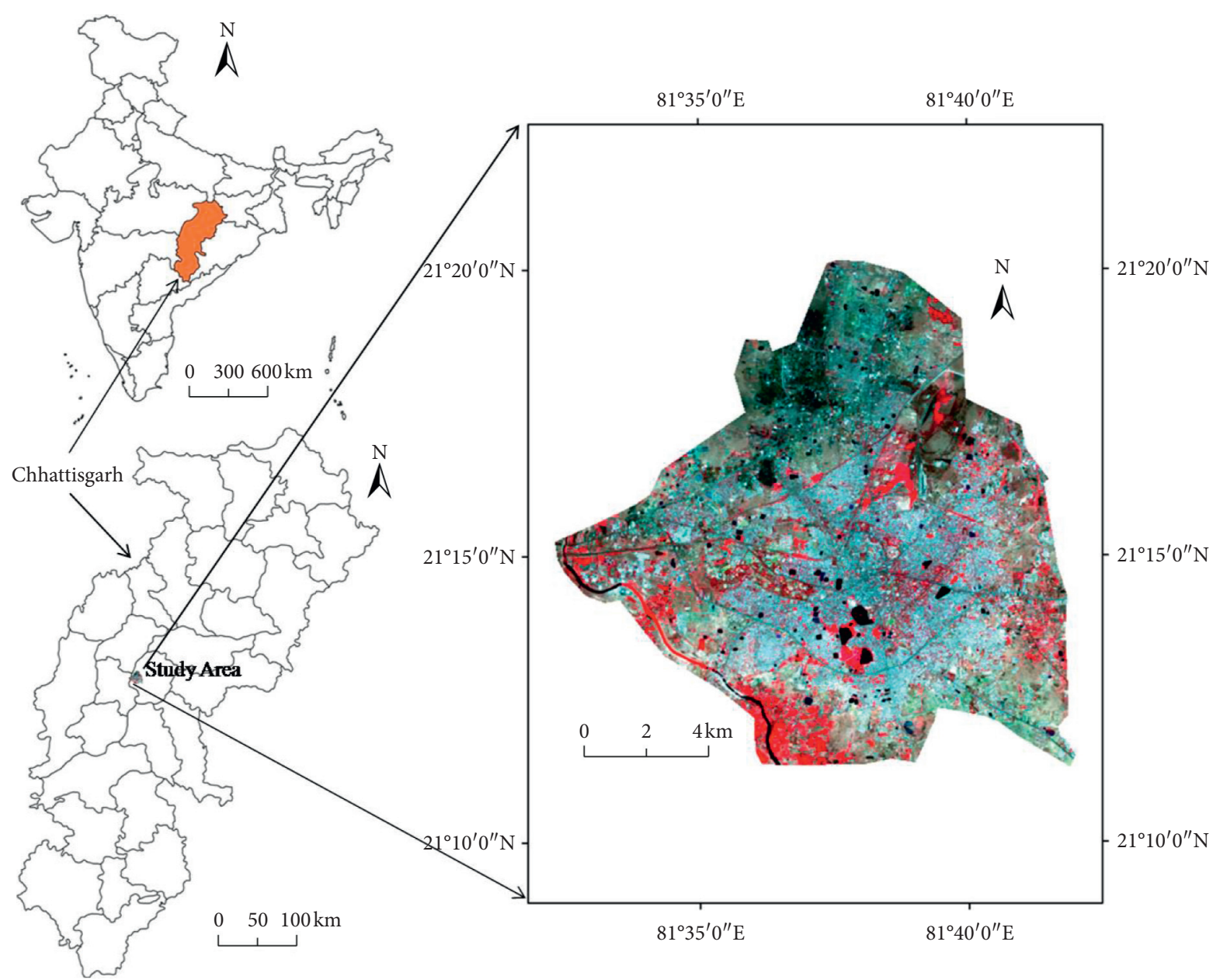

Figure 1: Location of the study area.

TABLe 1: Description of Landsat data from different sensors.

\begin{tabular}{|c|c|c|c|c|}
\hline Date of acquisition & Satellite sensor & Time & Path/row & Cloud cover $(\%)$ \\
\hline 25-Apr-2002 & Landsat 7 ETM+ & $04: 44: 54$ & $142 / 044$ & 0.00 \\
\hline 11-May-2002 & Landsat 7 ETM+ & $04: 44: 54$ & $142 / 044$ & 5.00 \\
\hline 28- Apr-2006 & Landsat 5 TM & 04:48:00 & $142 / 044$ & 2.00 \\
\hline 15-Jun-2006 & Landsat $5 \mathrm{TM}$ & $04: 48: 12$ & $142 / 044$ & 4.00 \\
\hline 07-Apr-2010 & Landsat $5 \mathrm{TM}$ & 04:47:02 & $142 / 044$ & 0.00 \\
\hline 23-Apr-2010 & Landsat $5 \mathrm{TM}$ & 04:46:59 & $142 / 044$ & 0.00 \\
\hline 25-May-2010 & Landsat $5 \mathrm{TM}$ & $04: 46: 51$ & $142 / 044$ & 0.00 \\
\hline 17-Mar-2014 & Landsat 8 OLI_TIRS & $04: 26: 36$ & $142 / 044$ & 0.00 \\
\hline 02-Apr-2014 & Landsat 8 OLI_TIRS & $04: 26: 19$ & $142 / 044$ & 0.00 \\
\hline 20-May-2014 & Landsat 8 OLI_TIRS & $04: 25: 38$ & $142 / 044$ & 5.46 \\
\hline 05-Jun-2014 & Landsat 8 OLI_TIRS & $04: 25: 45$ & $142 / 044$ & 0.02 \\
\hline 12-Mar-2018 & Landsat 8 OLI_TIRS & $04: 55: 43$ & $142 / 044$ & 2.10 \\
\hline 28-Mar-2018 & Landsat 8 OLI_TIRS & $04: 55: 36$ & $142 / 044$ & 0.01 \\
\hline 15-May-2018 & Landsat 8 OLI_TIRS & 04:55:08 & $142 / 044$ & 0.30 \\
\hline 16-Jun-2018 & Landsat 8 OLI_TIRS & 04:55:01 & $142 / 044$ & 2.31 \\
\hline
\end{tabular}

\section{Study Area and Data}

Raipur, the capital and the largest city of Chhattisgarh, India, was selected as the study area which extends between $21^{\circ} 11^{\prime} 22^{\prime \prime} \mathrm{N}$ to $21^{\circ} 20^{\prime} 02^{\prime \prime} \mathrm{N}$ and $81^{\circ} 32^{\prime} 20^{\prime \prime} \mathrm{E}$ to $81^{\circ} 41^{\prime} 50^{\prime \prime} \mathrm{E}$ with an elevation of $280-310 \mathrm{~m}$ (Figure 1). The average annual temperature of the city is around $27-30^{\circ} \mathrm{C}$. The entire work conducted on the hot and dry premonsoon months 
TABLE 2: Derivation of normalized difference vegetation index (NDVI).

\begin{tabular}{lccc}
\hline Acronym & Description & Formulation & Reference \\
\hline NDVI & Normalized difference vegetation index & (NIR - Red)/(NIR + Red)
\end{tabular}
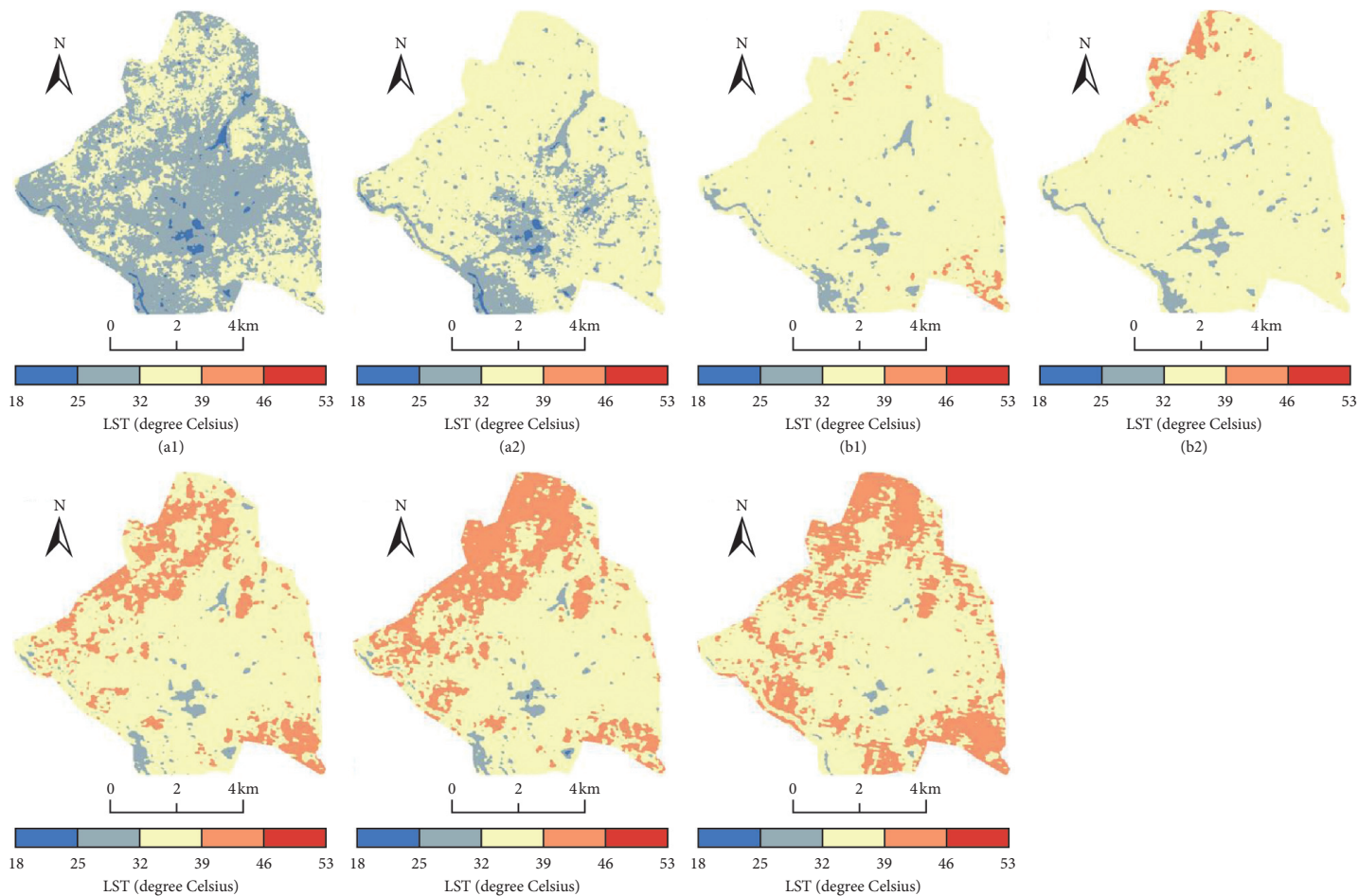

(c1)
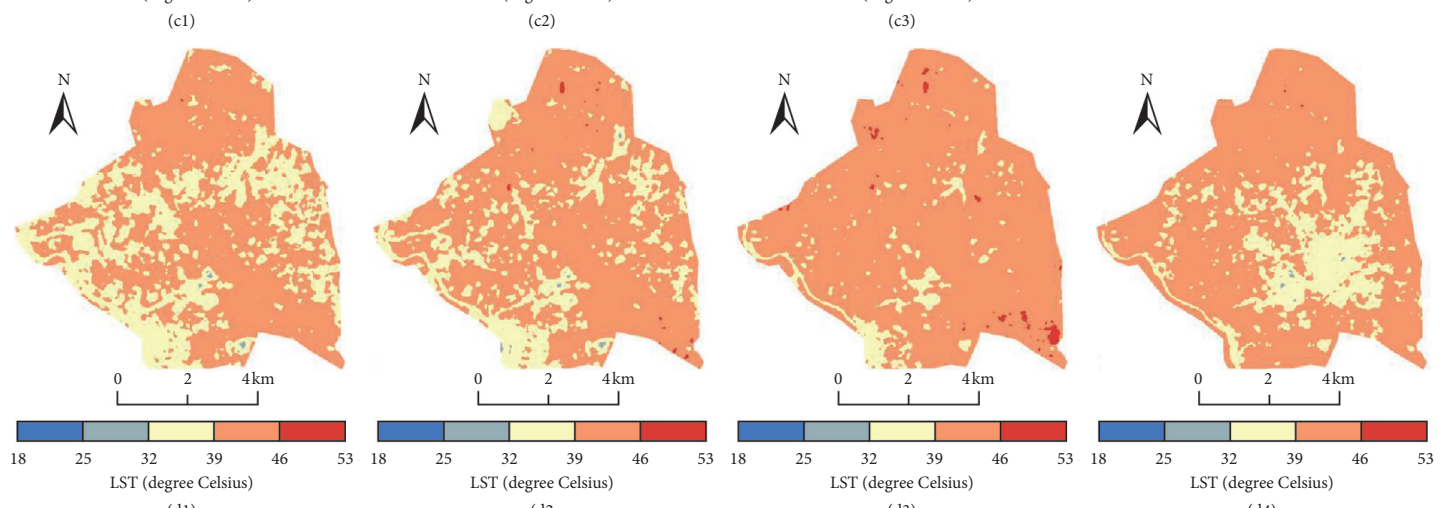

(d1)
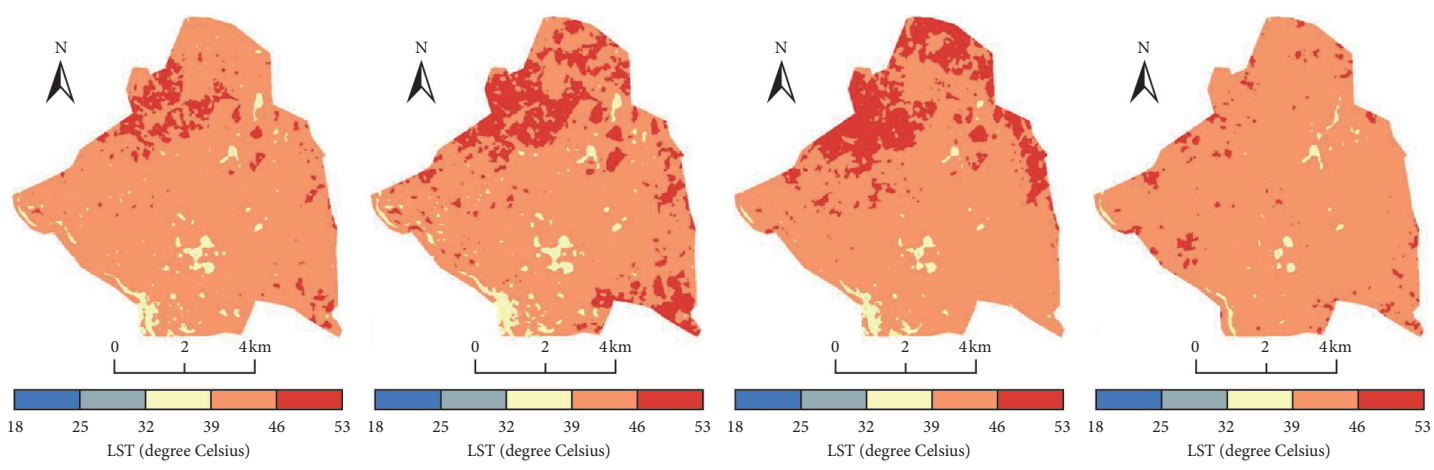

(e2)

(e4)

FIGURE 2: Variation in the distribution of LST ( $\left.{ }^{\circ} \mathrm{C}\right)$ : (a1-a2) 2002, (b1-b2) 2006, (c1-c3) 2010, (d1-d4) 2014, and (e1-e4) 2018. 
TABLE 3: Temporal variations in the distribution of LST (oC) (2002-2018).

\begin{tabular}{lcccc}
\hline Date & LST (minimum) & LST (maximum) & LST (mean) & LST (standard deviation) \\
\hline Mean 2002 & 22.08 & 36.56 & 31.91 & 1.82 \\
Mean 2006 & 25.83 & 41.83 & 35.62 & 2.06 \\
Mean 2010 & 25.82 & 43.35 & 37.42 & 2.22 \\
Mean 2014 & 31.26 & 47.27 & 40.49 & 2.03 \\
Mean 2018 & 33.98 & 50.40 & 43.53 & 2.11 \\
\hline
\end{tabular}

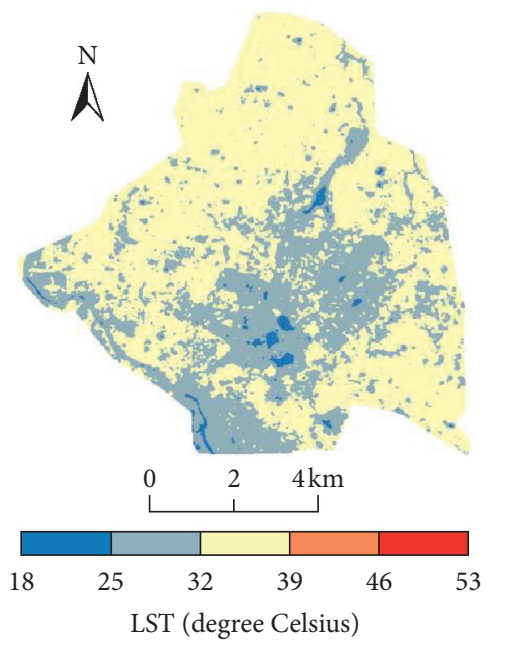

(a)

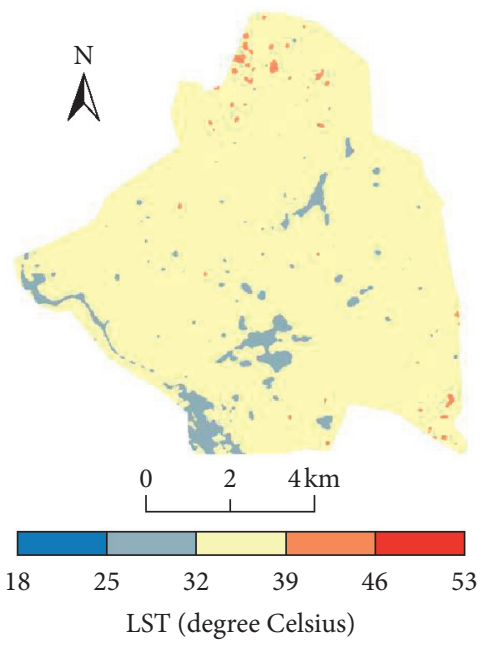

(b)

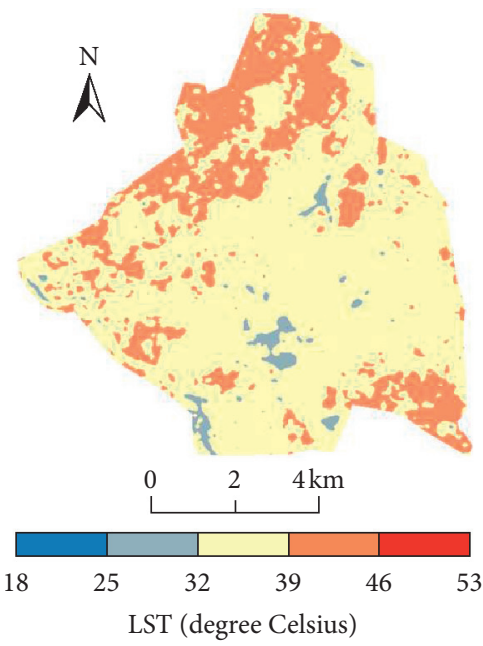

(c)

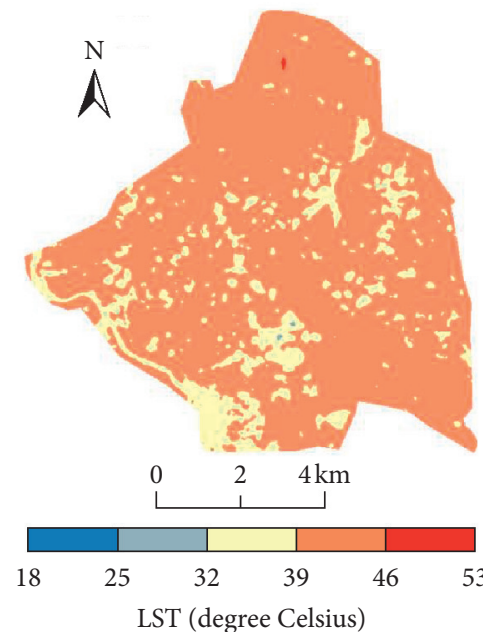

(d)

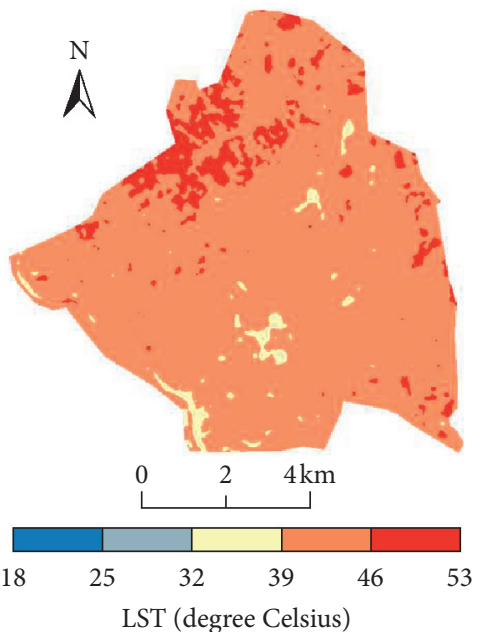

(e)

Figure 3: Distribution of mean LST ( $\left.{ }^{\circ} \mathrm{C}\right)$ : (a) 2002 (b) 2006 (c) 2010 (d) 2014 (e) 2018.

(March, April, May, and June). The range of the maximum temperature of the premonsoon months lies between $40-45^{\circ} \mathrm{C}$. The total population of Raipur is $1,010,087$. Literacy rate and sex ratio are $86.45 \%$ and 945 , respectively.

Five Landsat 5 Thematic Mapper (TM), two Landsat 7 Enhanced Thematic Mapper Plus (ETM+), and eight Landsat 8 Operational Land Imager (OLI)/Thermal Infrared Sensors (TIRS) data of premonsoon seasons with four years interval were freely downloaded from the United States Geological Survey website (https://earthexplorer.usgs.gov) to use in the present study (Table 1). Different types of
Landsat satellite sensors overpass the Raipur City of India between 04:25 and 04:56 Greenwich Mean Time (09:55 to 10: 26 AM Indian Standard Time). The data were obtained with maximum illumination which is needed in LST related study. ArcGIS 9.3 software was used to conduct the entire computation.

\section{Methodology}

Geometric correction, radiometric correction, and resampling are the required preprocessing steps for using the 
TABLE 4: Correlation coefficients between Landsat and MODIS sensors derived mean LST.

\begin{tabular}{lcc}
\hline Acquisition date (Landsat data) & Acquisition date (MODIS data) & Correlation coefficient \\
\hline 25-Apr-2002 & $25-$ Apr-2002 & 0.72 \\
11-May-2002 & 11 -May-2002 & 0.68 \\
28- Apr-2006 & 29 -Apr-2006 & 0.75 \\
15-Jun-2006 & $17-J u n-2006$ & 0.79 \\
07-Apr-2010 & $06-$ Apr-2010 & 0.71 \\
23-Apr-2010 & $22-$ Apr-2010 & 0.78 \\
25-May-2010 & $24-$ May-2010 & 0.67 \\
17-Mar-2014 & $16-$ Mar-2014 & 0.79 \\
02-Apr-2014 & $01-$ Apr-2014 & 0.76 \\
20-May-2014 & $19-$ May-2014 & 0.64 \\
05-Jun-2014 & $04-J u n-2014$ & 0.72 \\
12-Mar-2018 & $13-$ Mar-2018 & 0.62 \\
28-Mar-2018 & $27-$ Mar-2018 & 0.68 \\
15-May-2018 & $12-$ May-2018 & 0.70 \\
16-Jun-2018 & $15-J u n-2018$ & 0.73 \\
\hline
\end{tabular}

TABLE 5: Temporal variations in the distribution of NDVI for whole Raipur City (2002-2018).

\begin{tabular}{lcccc}
\hline Date of acquisition & NDVI (minimum) & NDVI (maximum) & NDVI (mean) & NDVI (standard deviation) \\
\hline Mean & -0.23 & 0.56 & 0.00 & 0.07 \\
Mean & -0.19 & 0.52 & 0.09 & 0.08 \\
Mean & -0.21 & 0.50 & 0.02 & 0.06 \\
Mean & -0.11 & 0.48 & 0.14 & 0.07 \\
Mean & -0.12 & 0.44 & 0.12 & 0.06 \\
\hline
\end{tabular}

Landsat images. LST was determined by using the TIR bands (band 6 for TM and ETM + data, and band 10 for OLI and TIRS data).

3.1. Image Preprocessing and Atmospheric Correction. The satellite data acquired from Landsat sensors were subset to limit the data size. The thermal infrared bands of Landsat sensors were resampled at $30 \mathrm{~m}$ resolution using the nearest neighbour algorithm to match the optical bands. Atmospheric correction of the satellite data was performed by the following steps.

For optical bands of Landsat data, the following equation is used to converting a Digital Number into spectral reflectance:

$$
\rho \lambda=M \rho \times Q_{c a l}+A \rho,
$$

where $\rho \lambda$ is the spectral reflectance at top-of-atmosphere (TOA) without correction for solar angle (Unitless), $Q_{c a l}$ is the Level 1 pixel value in Digital Number (DN), $M \rho$ is the reflectance multiplicative scaling factor for the band (REFLECTANCE_MULT_BAND_n from the metadata), and $A \rho$ is the reflectance additive scaling factor for the band (REFLECTANCE_ADD_BAND_N from the metadata). The $\rho \lambda$ is corrected with local sun elevation angle $\theta s$ by the following equation:

$$
\rho^{\prime} \lambda=\frac{\rho \lambda}{\sin (\theta s)}
$$

For TIR band of Landsat data, a similar calibration equation is used:

$$
L \lambda=M L \times Q_{c a l}+A L,
$$

where $L \lambda$ is the spectral radiance at TOA in $\mathrm{Wm}^{-2} \mathrm{sr}^{-1} \mathrm{~mm}^{-1}, Q_{c a l}$ is the Level 1 pixel value in Digital Number $(\mathrm{DN}), M L$ is the radiance multiplicative scaling factor for the band (RADIANCE_MULT_BAND_n from the metadata), and $A L$ is radiance additive scaling factor for the band (RADIANCE_ADD_BAND_n from the metadata).

3.2. LST Estimation Using Landsat Satellite Sensors. In the present study, the LST was determined by using the monowindow algorithm [55] in which the three necessary elements are atmospheric transmittance, ground emissivity, and effective mean atmospheric temperature.

The original TIR bands of Landsat datasets were resampled into $30 \mathrm{~m}$. The equations are as follows:

$$
L_{\lambda}=\text { RadianceMultiBand } \times \mathrm{DN}+\text { RadianceAddBand, }
$$

where $L_{\lambda}$ is spectral radiance $\left(\mathrm{Wm}^{-2} \mathrm{sr}^{-1} \mathrm{~mm}^{-1}\right)$.

$$
T_{b}=\frac{K_{2}}{\ln \left(\left(K_{1} / L_{\lambda}\right)+1\right)},
$$

where $T_{b}$ is the at-sensor brightness temperature (Kelvin); $K_{2}$ and $K_{1}$ are calibration constants for Landsat datasets. 

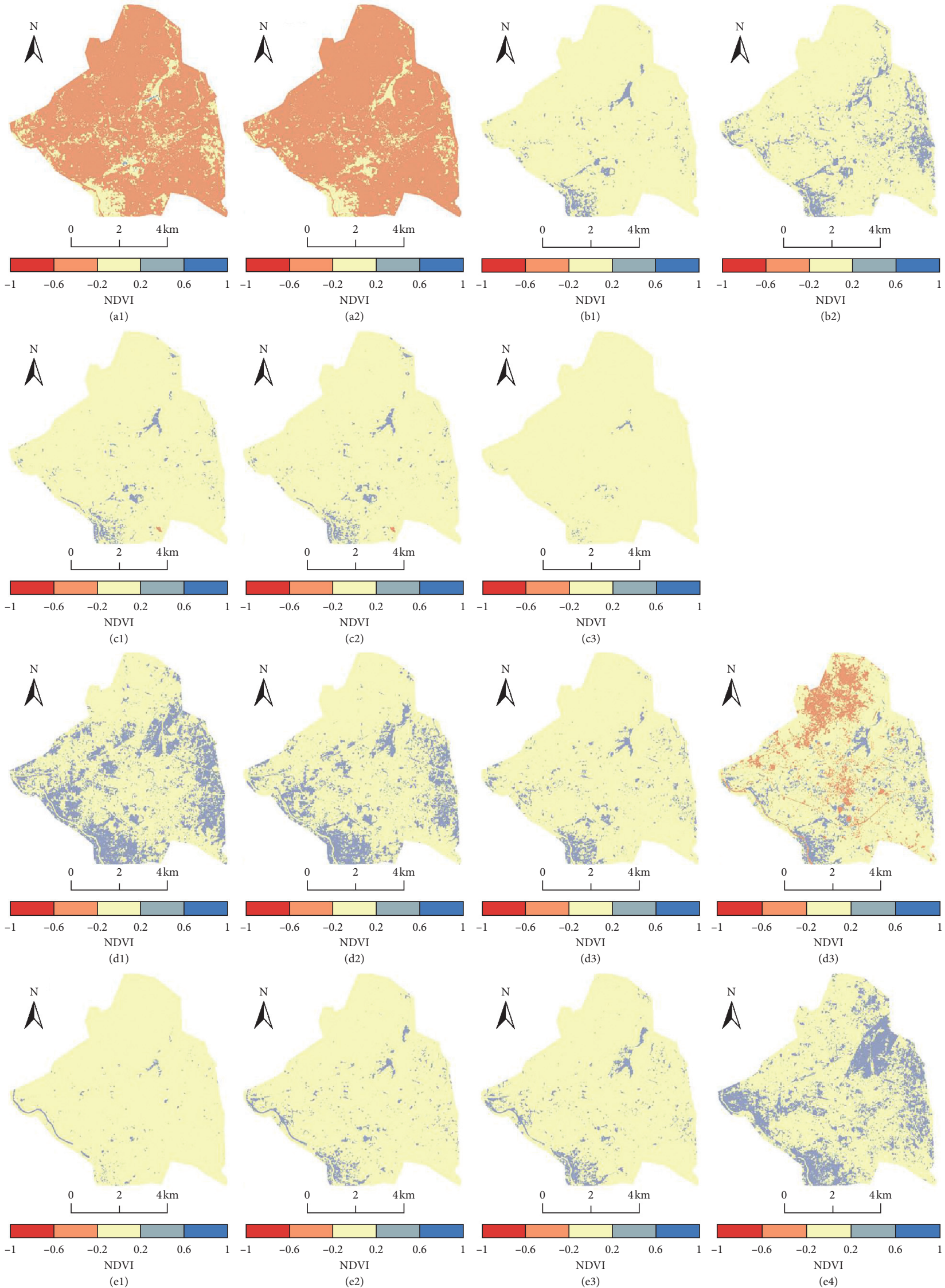

FIgURE 4: Variation in the distribution of NDVI: (a1-a2) 2002 (b1-b2) 2006 (c1-c3) 2010 (d1-d4) 2014 (e1-e4) 2018. 


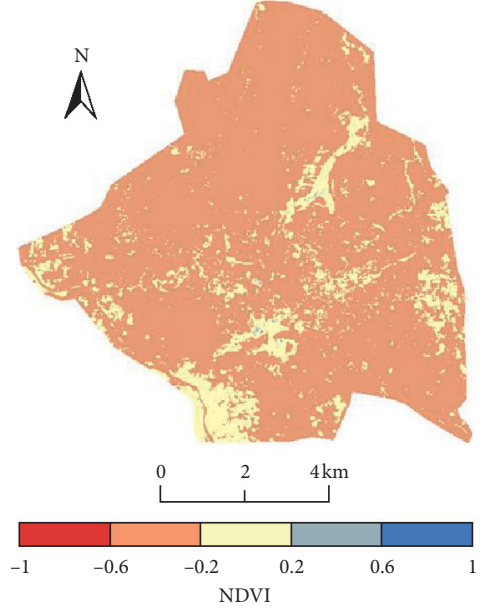

(a)

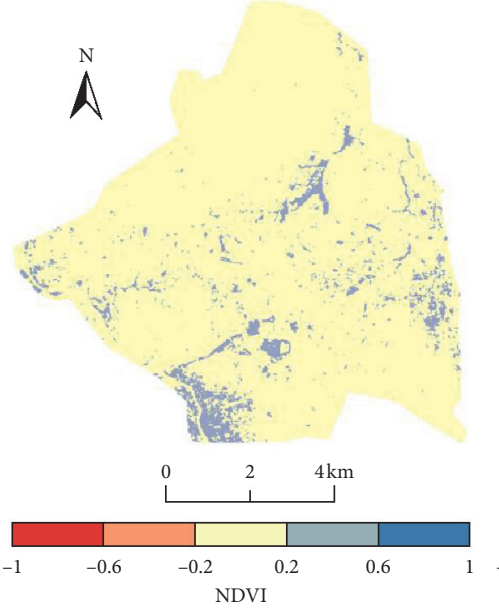

(b)

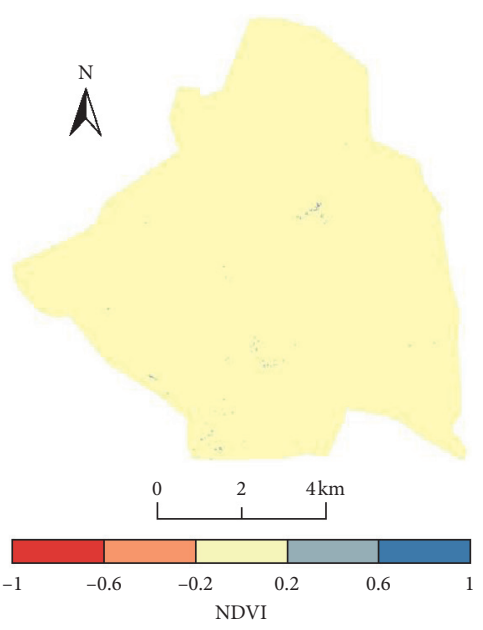

(c)
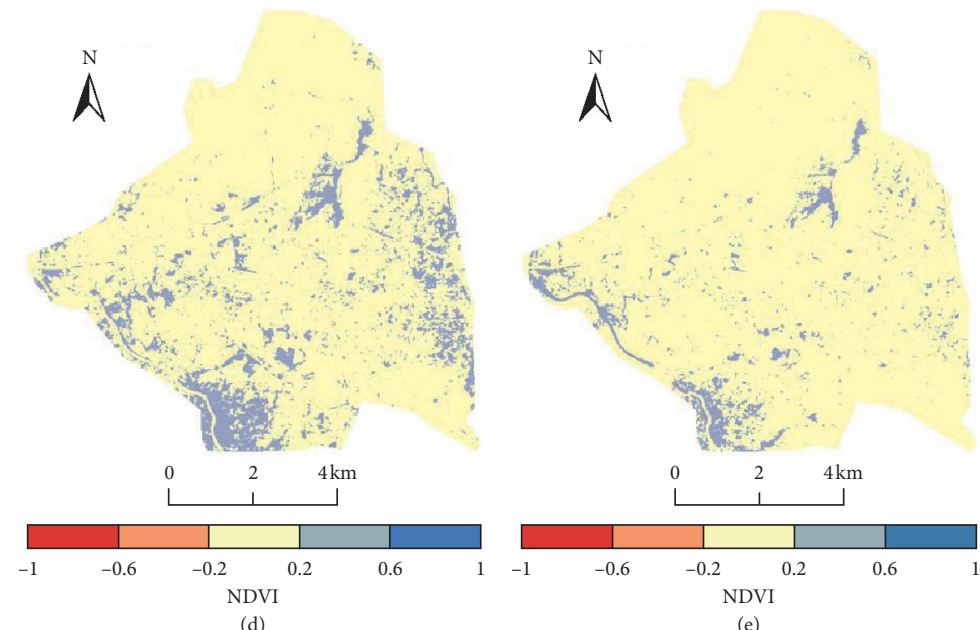

(e)

Figure 5: Distribution of mean NDVI: (a) 2002, (b) 2006, (c) 2010, (d) 2014, and (e) 2018.

$$
F_{v}=\left(\frac{N D V I-N D V I}{\min }{ }^{2}\right.
$$

where $\mathrm{NDVI}_{\min }$ is the minimum value (0.2) of NDVI for bare soil pixel and $\mathrm{NDVI}_{\max }$ is the maximum value (0.5) of NDVI for healthy vegetation pixel.

$\mathrm{d} \varepsilon$ is the geometric distribution effect for the natural surface and internal reflection. The value of $\mathrm{d} \varepsilon$ may be $2 \%$ for mixed and elevated land surfaces.

$$
\mathrm{d} \varepsilon=\left(1-\varepsilon_{s}\right)\left(1-F_{v}\right) F \varepsilon_{v},
$$

where $\varepsilon_{s}$ is soil emissivity; $F_{v}$ is fractional vegetation; $F$ is a shape factor (0.55); and $\varepsilon_{v}$ is vegetation emissivity.

$$
\varepsilon=\varepsilon_{v} F_{v}+\varepsilon_{s}\left(1-F_{v}\right)+\mathrm{d} \varepsilon,
$$

where $\varepsilon$ is land surface emissivity. The value of $\varepsilon$ is calculated by the formula given below:

$$
\varepsilon=0.004 \times F_{v}+0.986 .
$$

Water vapour content is determined by the following equation:

$$
\begin{aligned}
w= & 0.0981 \times\left[10 \times 0.6108 \times \exp \left(\frac{17.27 \times\left(T_{0}-273.15\right)}{237.3+\left(T_{0}-273.15\right)}\right)\right. \\
& \times \mathrm{RH}]+0.1697,
\end{aligned}
$$

where $w$ is water vapour content $\left(\mathrm{g} / \mathrm{cm}^{2}\right) ; T_{0}$ is near-surface air temperature (Kelvin); RH is relative humidity (\%). The information on these parameters was provided by the Meteorological Centre, Raipur.

$$
\tau=1.031412-0.11536 w,
$$

where $\tau$ is the total atmospheric transmittance.

The effective mean atmospheric transmittance of Raipur City was determined as follows [33]: 

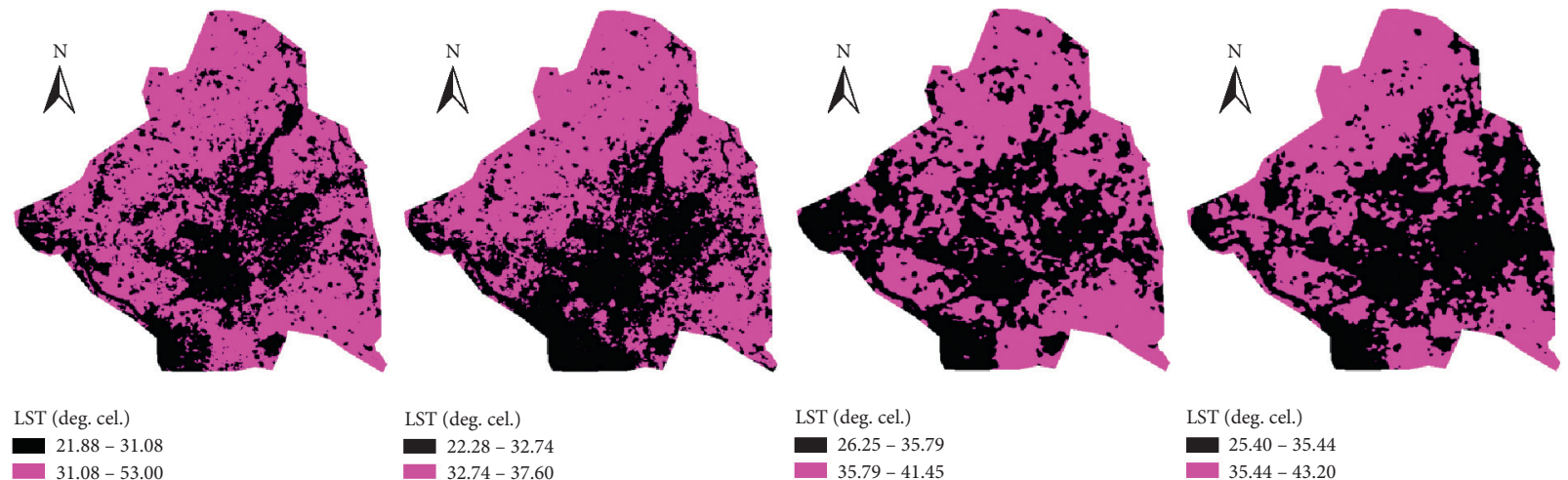

LST (deg. cel.)
$22.28-32.74$

LST (deg. cel.)
$26.25-35.79$
$35.79-41.45$

LST (deg. cel.)

- $31.08-53.00$

$32.74-37.60$

$25.40-35.44$

(a1)
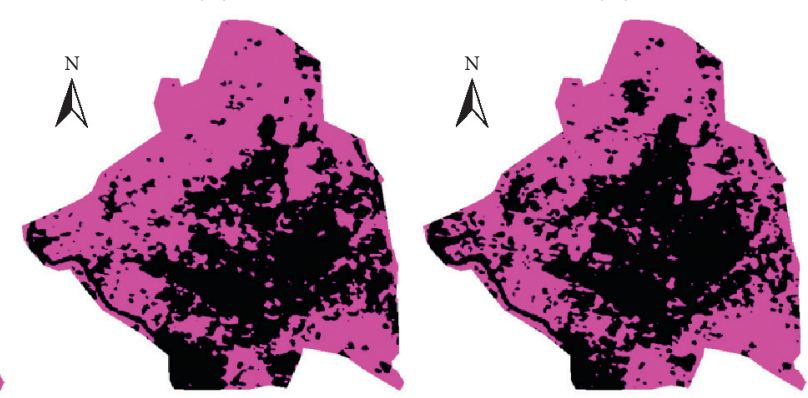

(b2)

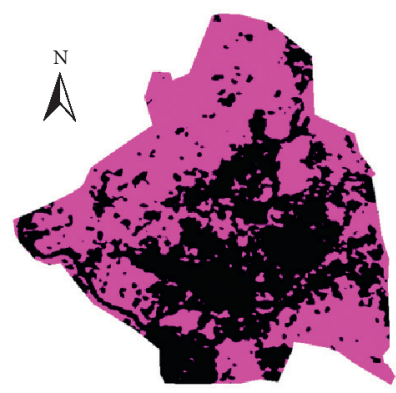

LST (deg. cel.)

LST (deg. cel.)

$25.31-36.94$
$36.94-43.93$

$24.15-37.39$
$37.39-44.60$

LST (deg. cel.)

(c1)

(c2)
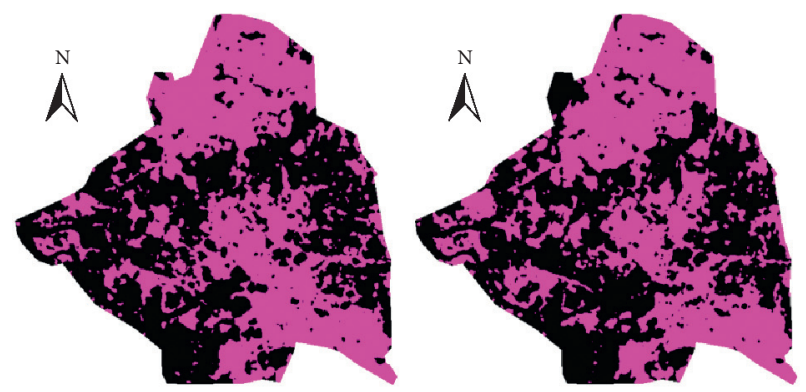

$28.01-37.91$
$37.91-41.58$
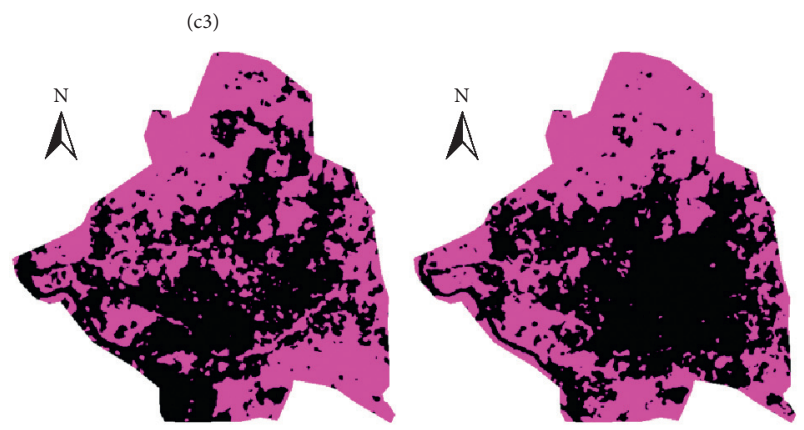

LST (deg. cel.)
$31.48-39.60$
$39.60-46.63$

LST (deg. cel.)
$30.72-40.27$

LST (deg. cel.)
$30.07-41.90$

LST (deg. cel.)

$40.27-47.87$

$41.90-47.66$

$31.01-40.46$
$40.46-47.28$

(d1)

(d2)
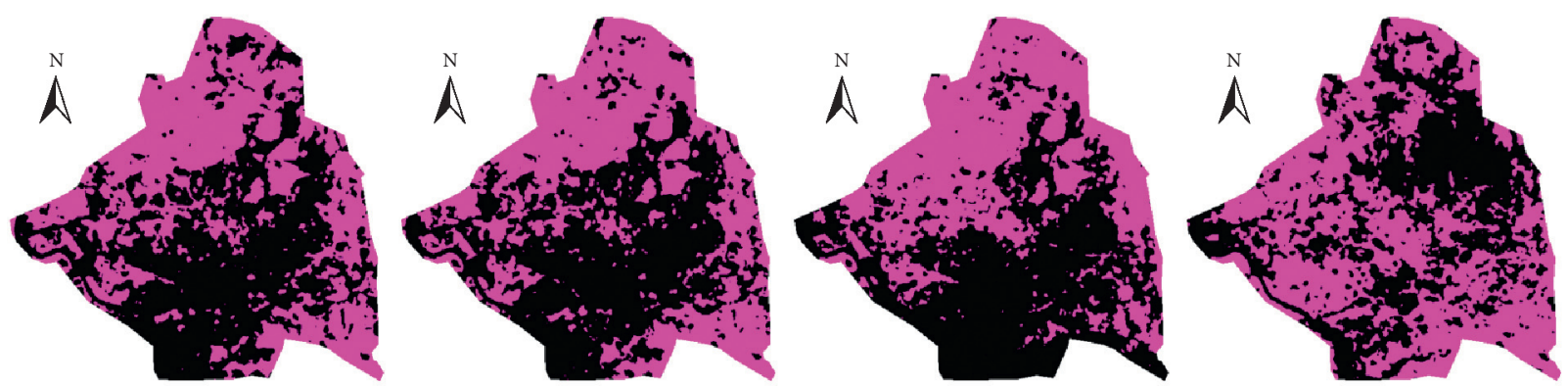

LST (deg. cel.)
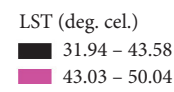

LST (deg. cel.)
$35.10-43.99$
$43.99-51.64$

LST (deg. cel.)

- $35.69-43.52$

(e3)

FIGURE 6: The area above mean LST (pink portion) and the area below mean LST (black portion): (a1-a2) 2002, (b1-b2) 2006, (c1-c3) 2010, (d1-d4) 2014, and (e1-e4) 2018. 

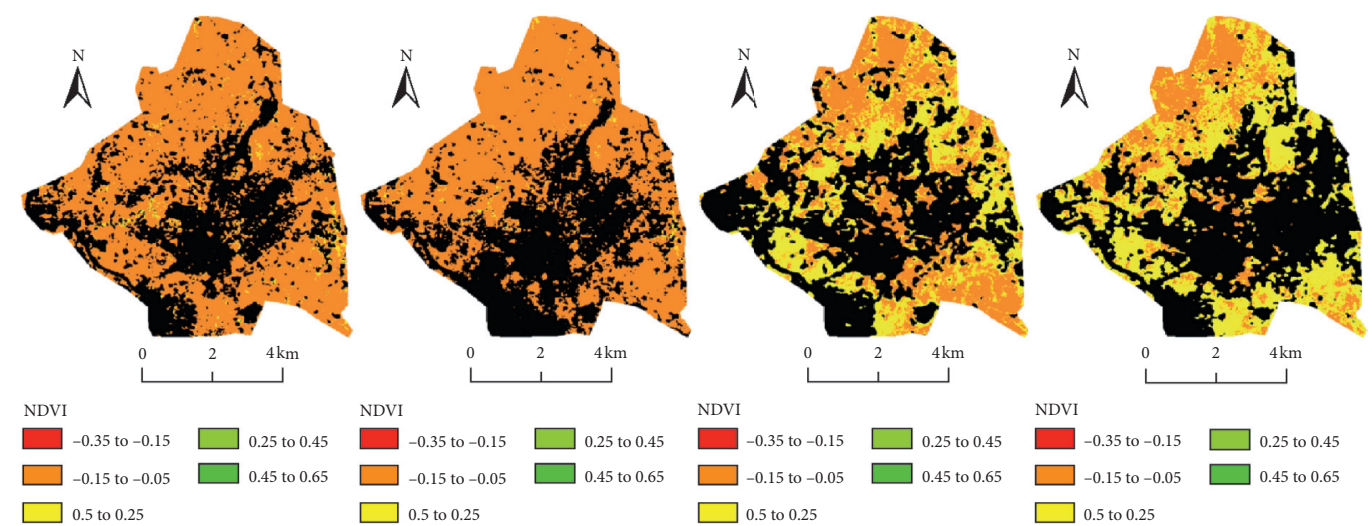

NDVI

$\square-0.15$ to -0.05

$\square-0.35$ to $-0.15 \quad \square 0.25$ to 0.45
$\square-0.15$ to $-0.05 \quad \square 0.45$ to 0.65

NDVI

$\square-0.15$ to -0.05
$\square 0.5$ to 0.25

0.5 to 0.25

$\square 0.5$ to 0.2
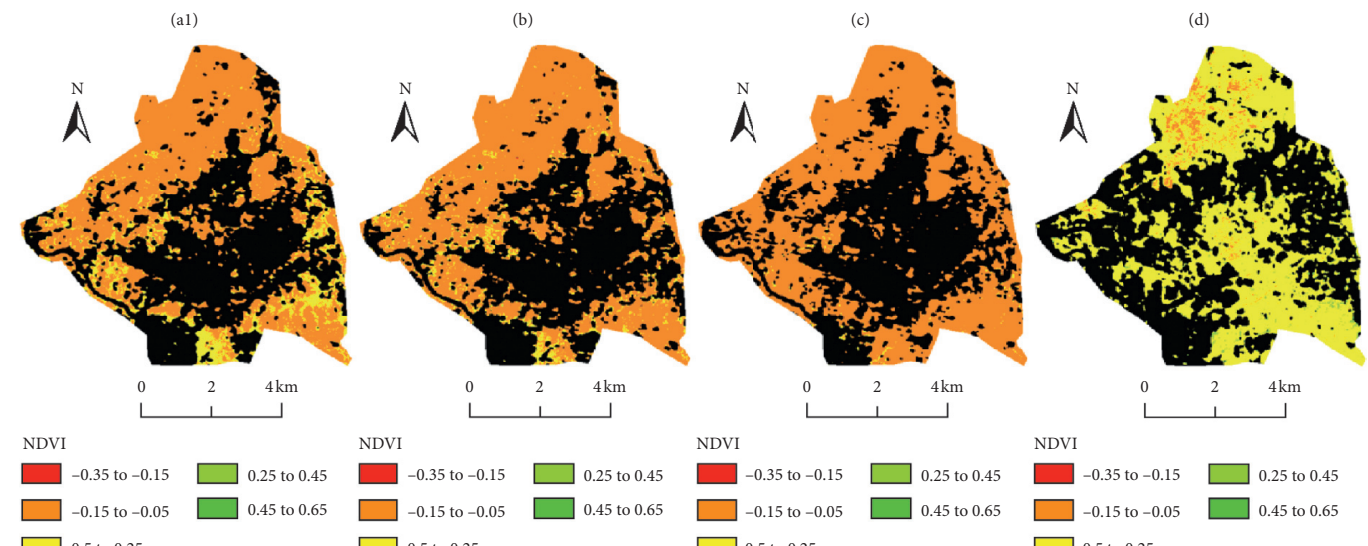

NDVI
$\square-0.35$ to $-0.15 \quad \square 0.25$ to 0.45
$\square-0.15$ to $-0.05 \quad \square 0.45$ to 0.65

-0.15 to -0.05

$\square .5$ to 0.25

$\square 0.5$ to 0.25

$\square 0.5$ to 0.25
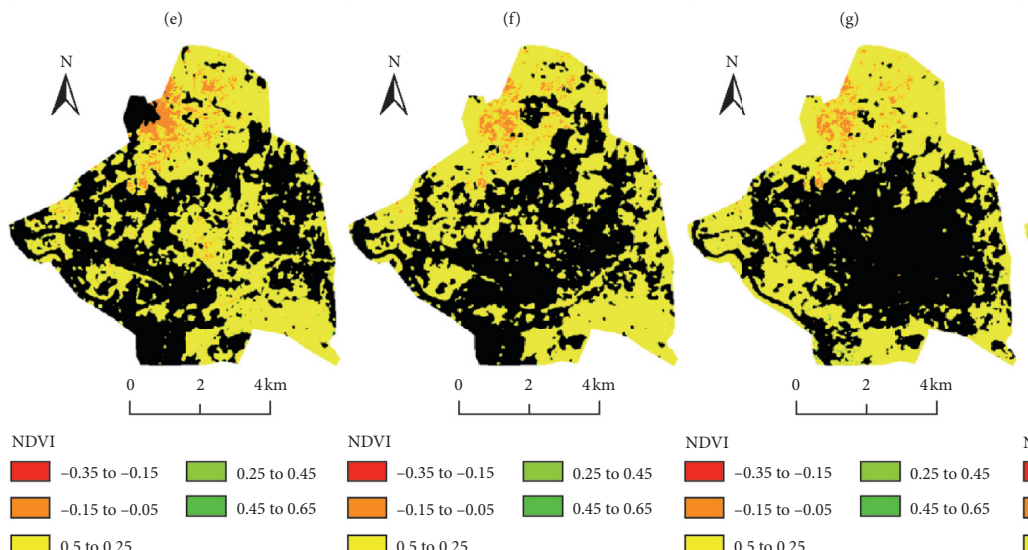

NDVI

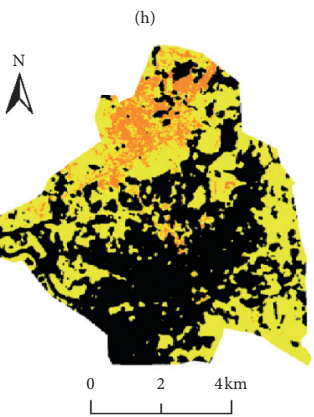
0.5 to 0.25

$\square 0.5$ to 0.25

$\square-0.15$ to $-0.05 \quad \square 0.45$ to 0.65
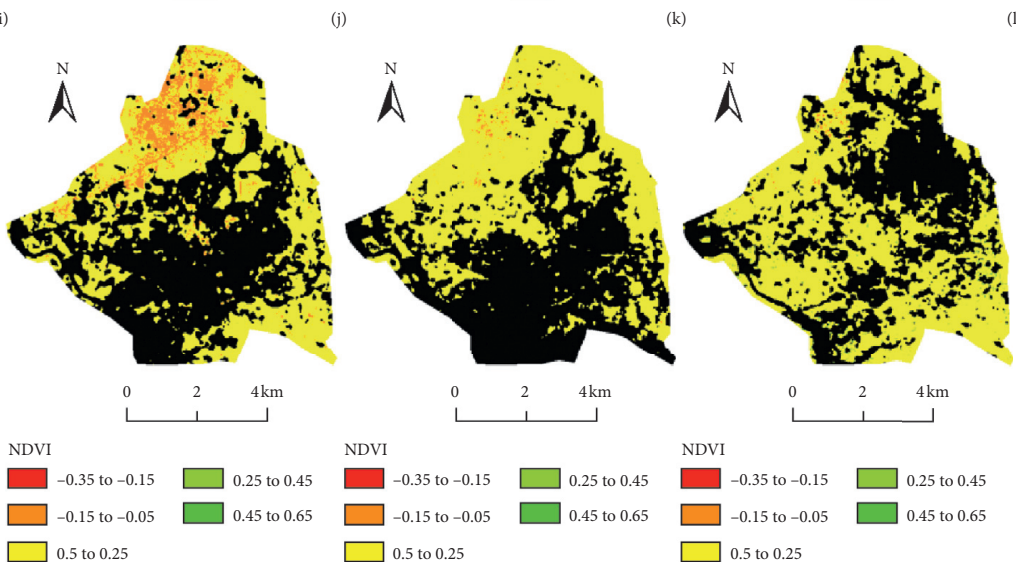

(n)

FIGURE 7: NDVI in the area above mean LST: (a-b) 2002, (c-d) 2006, (e-g) 2010, (h-k) 2014, and (l-o) 2018. The black portion of the maps shows the area below mean LST. 
TABLE 6: Temporal variations of NDVI in the area above mean LST (2002-2018).

\begin{tabular}{lcccc}
\hline Year & NDVI (minimum) & NDVI (maximum) & NDVI (mean) & NDVI (standard deviation) \\
\hline Mean 2002 & -0.14 & 0.21 & -0.02 & 0.03 \\
Mean 2006 & -0.09 & 0.34 & 0.06 & 0.05 \\
Mean 2010 & -0.18 & 0.30 & 0.01 & 0.04 \\
Mean 2014 & -0.03 & 0.39 & 0.12 & 0.05 \\
Mean 2018 & -0.08 & 0.34 & 0.11 & 0.04 \\
\hline
\end{tabular}

$$
\begin{aligned}
T_{a} & =17.9769+0.91715 T_{0}, \\
T_{s} & =\frac{\left[a(1-C-D)+(b(1-C-D)+C+D) T_{b}-D T_{a}\right]}{C}, \\
C & =\varepsilon \tau, \\
D & =(1-\tau)[1+(1-\varepsilon) \tau],
\end{aligned}
$$

where $T_{a}$ is mean atmospheric temperature and $T_{s}$ is land surface temperature; $a=-67.355351$ and $b=0.458606$.

3.3. NDVI Estimation Using Landsat Sensors. Many previous research works applied various remote sensing indices to extract various land use classes $[8,18,23,24,33,34,49,56]$. Here, only NDVI was applied to correlate with LST. NDVI can be used to estimate other LULC types along with green vegetation [33,57-60]. Red and NIR bands of Landsat data are used to determine NDVI (Table 2).

\section{Results and Discussion}

4.1. Spatiotemporal Contrast in the Distribution of LST. Figure 2 presents the distribution of LST in the premonsoon months from 2002 to 2018 with a four years interval (Table 3$)$. The average of annual mean LST value lies between $31.91^{\circ} \mathrm{C}(2002)$ and $43.53^{\circ} \mathrm{C}(2018)$. The north-west and the southeast parts of the study area, which are under open bare land, experience higher LST values. The lower values of LST are observed in central regions of the city because of the presence of park, scattered trees, wetlands, and water bodies (Figure 3).

4.2. Validation of the Result by Using Other Satellite Data. Any satellite retrieved LST needs a proper validation with an in situ measurement or other satellite retrieved LST [2]. Here, MODIS data were used to validate the values of LST. As MODIS and Landsat sensors cannot pass over the same region in a particular date, MOD11A1 data (resolution $-1 \mathrm{~km}$ ) of the following particular dates (Table 4) were used to validate for the resulting LST. These particular dates were free from any cloud coverage or precipitation. TIR bands of MODIS sensor $(1 \mathrm{~km})$ and Landsat sensors $(120 \mathrm{~m}, 120 \mathrm{~m}$, and $100 \mathrm{~m}$ for Landsat 5, 7, and 8 sensors, respectively). Landsat and MODIS sensors provide a slightly different value of LST due to water vapour content, resampling method, and different passing time of the sensors
[56]. After performing the downscaling process, a significant correlation coefficient was found between the Landsat derived mean LST and corresponding MODIS derived mean downscaled LST (Table 4).

4.3. Variation in NDVI Distribution for Multitemporal Landsat Data. Red and NIR bands are required to derive the formula of NDVI [60]. Table 5 represents the value of NDVI for the Landsat satellite images during the study period. Figure 4 presents the spatial and temporal status of NDVI for the whole study area, date-wise and year-wise. Southwest and northeast portions of the city reflect higher NDVI values due to high percentage of green vegetation. The average values of maximum NDVI were gradually decreased (0.56 in 2002, 0.52 in 2006, 0.50 in 2010, 0.48 in 2014 , and 0.44 in 2018) since the beginning of the study. It means that vegetation was lost at a substantial rate. The spatial distribution of LST and NDVI exhibits an opposite direction (Figure 5).

4.4. Spatiotemporal Distribution of NDVI during the Entire Period. Figure 6 shows the area above mean LST (pink part) and the area below mean LST (black part) for every single image during the period of study. Figure 7 and Table 6 represent the temporal variation in the NDVI distribution values for the area has more than mean LST during the entire period. The black portion of the maps shows the area below mean LST (Figure 7). Generally, it seems to have an increase in NDVI values with time. But, there is no such particular pattern of increase of NDVI. 2014 and 2018 have greater NDVI values (maximum and mean NDVI) than the earlier years.

Figure 8 and Table 7 represent the temporal variation in the spatial distribution of NDVI values in the area below mean LST. The black portion of the maps shows the area above mean LST (Figure 8). A steady decreasing trend has been observed in the values of mean NDVI. The value of maximum NDVI is much higher in the area below mean LST than in the area above mean LST.

Figure 9 shows the graphical presentation of the spatial and temporal change of mean NDVI for the area having less than mean LST, the area having more than mean LST, and the whole area of the city. The overall trend is increasing in nature. In 2006, the mean NDVI values were more than in 2002. The values were reduced again in 2010. From 2010 to 2014, a high slope was found in mean NDVI values. In 2014 and 2018, the trend line was quite stable. It is clear from Figure 9 that mean NDVI values are higher for Landsat 8 

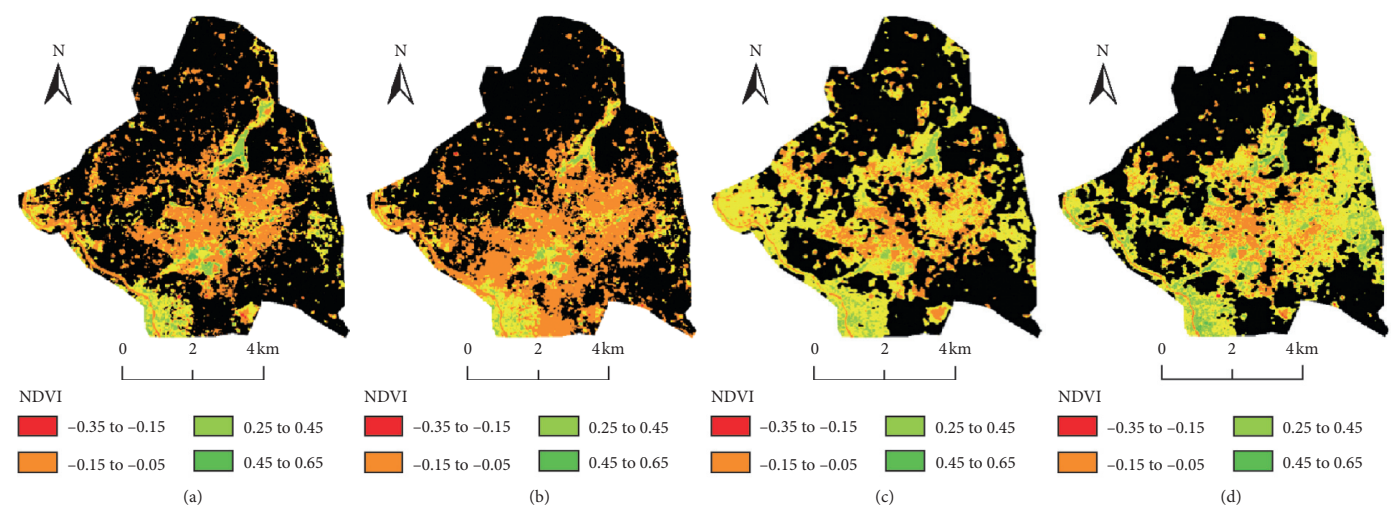

NDVI
$\square-0.35$ to $-0.15 \quad \square 0.25$ to 0.45
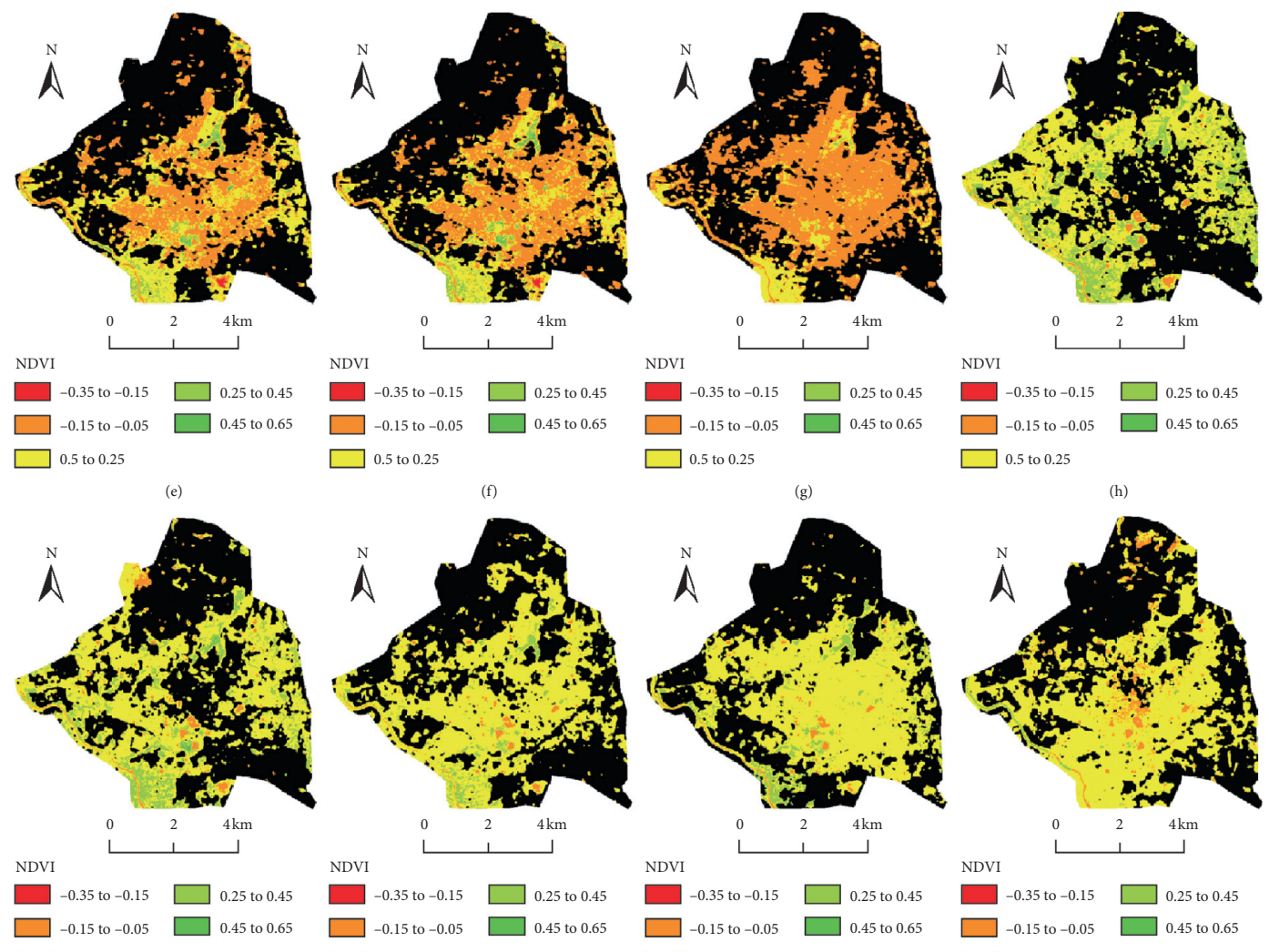

$\square-0.15$ to -0.05

$\square 0.5$ to 0.25

$\square .5$ to 0.25

NDVI

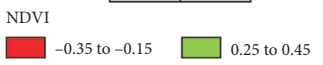

$\square-0.15$ to $-0.05 \quad \square 0.45$ to 0.65
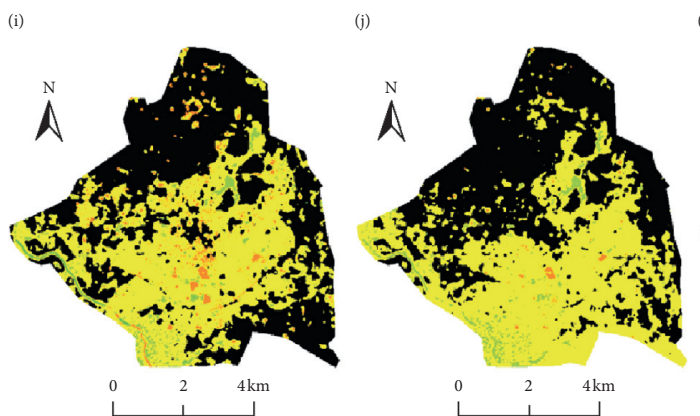

(k) (1)
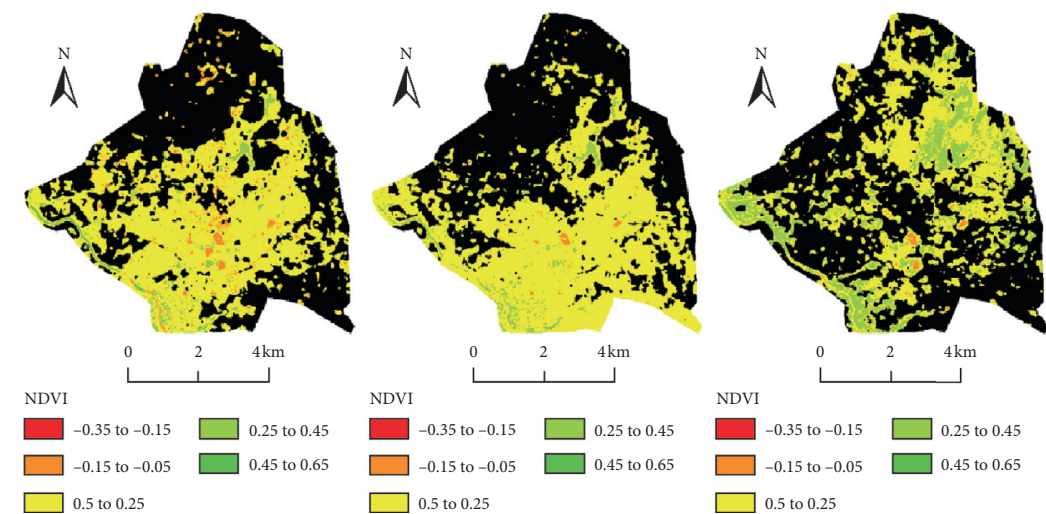

$(\mathrm{m})$

Figure 8: NDVI in the area below mean LST: (a-b) 2002, (c-d) 2006, (e-g) 2010, (h-k) 2014, and (l-o) 2018. The black portion of the maps shows the area above mean LST. 
TABLE 7: Temporal variations of NDVI in the area below mean LST (2002-2018).

\begin{tabular}{lcccc}
\hline Date of acquisition & NDVI (minimum) & NDVI (maximum) & NDVI (mean) & NDVI (standard deviation) \\
\hline Mean & -0.23 & 0.57 & 0.04 & 0.10 \\
Mean & -0.19 & 0.52 & 0.11 & 0.09 \\
Mean & -0.21 & 0.50 & 0.04 & 0.08 \\
Mean & -0.11 & 0.48 & 0.17 & 0.07 \\
Mean & -0.12 & 0.44 & 0.14 & 0.06 \\
\hline
\end{tabular}

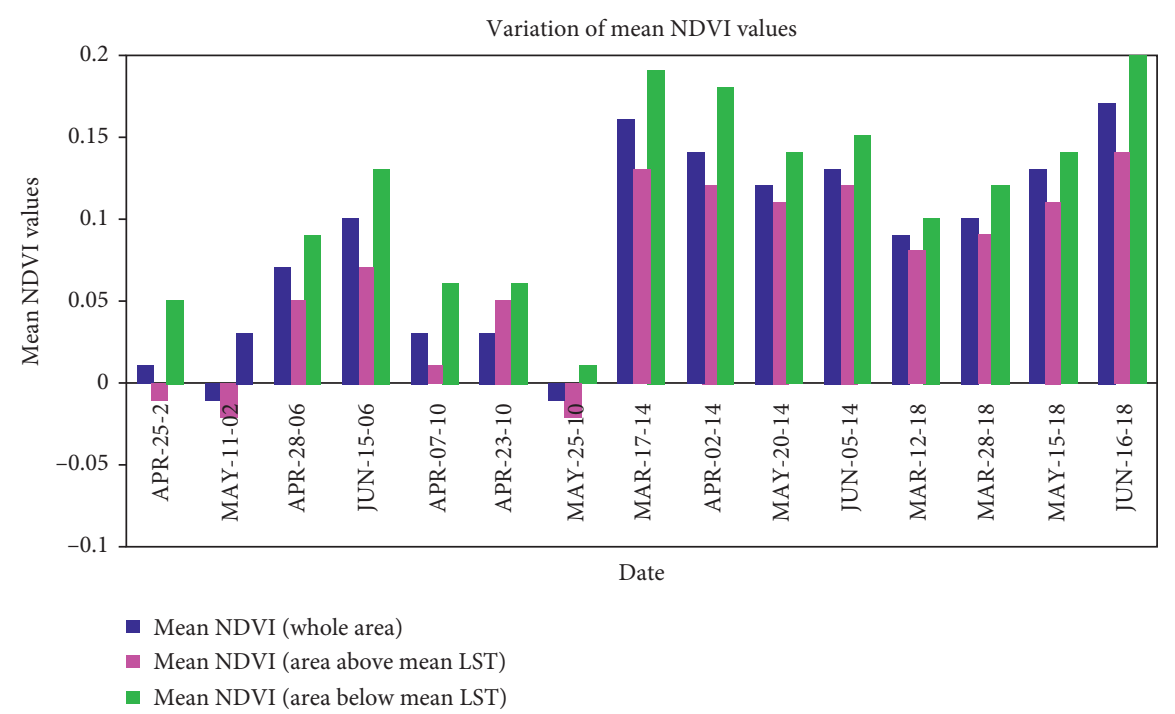

Figure 9: Temporal variation of mean NDVI for each satellite image.

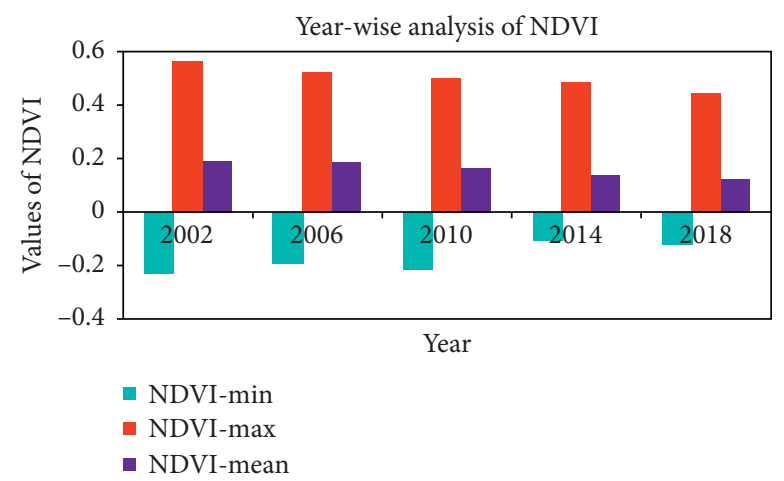

Figure 10: Year-wise analysis of NDVI.

data, whereas these values were lower for Landsat 5 or Landsat 7 data. This variation of mean NDVI in different Landsat sensors is mainly due to the configuration of the sensors as the spectral resolution of NIR band of Landsat 8 data $(0.851-0.879 \mu \mathrm{m}$ wavelength) is different from the NIR band of Landsat 5 data $(0.760-0.900 \mu \mathrm{m}$ wavelength) or Landsat 7 data $(0.770-0.900 \mu \mathrm{m}$ wavelength). Further, the year-wise analysis of NDVI has been shown in Figure 10. The diagram shows that the values of maximum NDVI are gradually decreasing with time, whereas the values of minimum NDVI and mean NDVI are increasing. The result is quite significant as it reflects the loss of urban vegetation within the entire time period.
4.5. LST-NDVI Correlation in the Whole City, Above Mean LST Areas, and Below Mean LST Area. LST builds a strong to moderate stable negative correlation with NDVI in the whole Raipur City during the study period. Figure 11 shows a date-wise correlation. The LST-NDVI correlation is moderate to strong negative for the whole area, whereas the correlation does not show any specific pattern for below mean LST zones and above mean LST zones, separately. Figure 12 shows a year-wise correlation. The negativity was almost gradually decreased with time. In the area above mean LST, this correlation is moderately negative and it is stable as these regions mainly cover a high proportion of urban vegetation. In the area below mean LST, LST builds a 


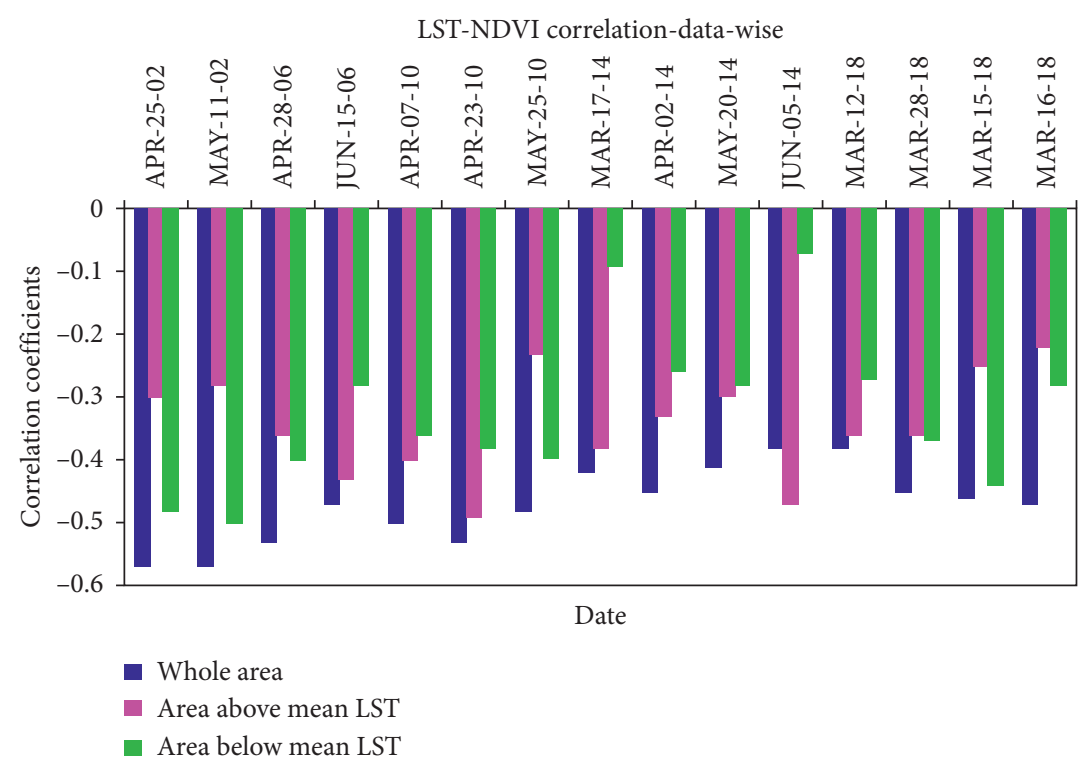

Figure 11: Date-wise LST-NDVI correlation analysis.

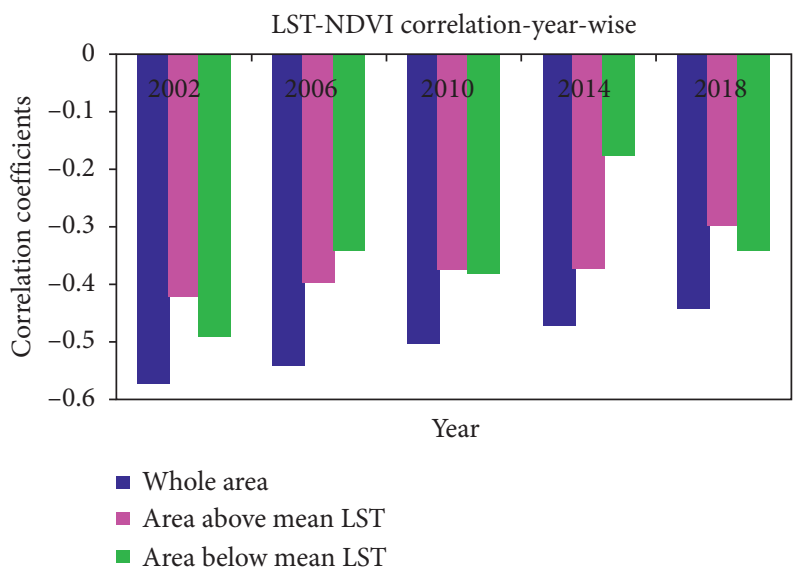

FIgURE 12: Year-wise LST-NDVI correlation analysis.

moderate to weak correlation with NDVI and some fluctuations are present in this relationship due to the different land compositions.

\section{Conclusion}

The present study monitors the LST-NDVI correlation using different Landsat satellite sensors of the premonsoon season for a specific time interval. Mean LST was a significant measurement for the study as it performs in the area above mean LST as well as in the area below mean LST along with the whole Raipur City. From 2002 to 2018 premonsoon months, the LST was increased by $11.62^{\circ} \mathrm{C}$. The LST-NDVI correlation was negative for the study area throughout the period. For Landsat 8 data, mean NDVI values are higher than the other Landsat sensors and thus, the mean NDVI values become higher in recent times. The area below mean LST has a weaker correlation than the area above mean LST. The strength of the correlation was reduced gradually with time. Future urban and environmental planning in the premonsoon season can be implemented using the spatiotemporal variation of LST-NDVI relationship.

\section{Data Availability}

The data used to support the findings of this study are included within the article.

\section{Conflicts of Interest}

The authors declare that they have no conflicts of interest.

\section{References}

[1] H. Govil, S. Guha, P. Diwan, N. Gill, and A. Dey, "Evaluation of ASTER TIR data-based lithological indices in parts of Madhya Pradesh and Chhattisgarh State, India," in Data Management, Analytics and Innovation, N. Sharma, A. Chakrabarti, and V. Balas, Eds., vol. 1042, Springer, Advances in Intelligent Systems and Computing, pp. 161-169, Springer, 2020a.

[2] S. Guha and H. Govil, "An assessment on the relationship between land surface temperature and normalized difference vegetation index," Environment, Development and Sustainability, 2020.

[3] X. Hao, W. Li, and H. Deng, "The oasis effect and summer temperature rise in arid regions-case study in Tarim Basin," Scientific Reports, vol. 6, no. 1, p. 35418, 2016.

[4] C. J. Tomlinson, L. Chapman, J. E. Thornes, and C. Baker, "Remote sensing land surface temperature for meteorology and climatology: a review," Meteorological Applications, vol. 18, no. 3, pp. 296-306, 2011.

[5] G. L. Hou, H. Y. Zhang, Y. Q. Wang, Z. H. Qiao, and Z.X. Zhang, "Retrieval and spatial distribution of land surface temperature in the middle part of Jilin province based on MODIS data," Scientia Geographica Sinica, vol. 30, pp. 421427, 2010.

[6] W. Li, Q. Cao, K. Lang, and J. Wu, "Linking potential heat source and sink to urban heat island: heterogeneous effects of 
landscape pattern on land surface temperature," Science of The Total Environment, vol. 586, pp. 457-465, 2017.

[7] X. L. Yuan, W. Wang, J. Cui, F. Meng, A. Kurban, and P. De Maeyer, "Vegetation changes and land surface feedbacks drive shifts in local temperatures over Central Asia," Scientific Reports, vol. 7, no. 1, p. 3287, 2017.

[8] S. Guha, H. Govil, A. Dey, and N. Gill, "Analytical study of land surface temperature with NDVI and NDBI using Landsat 8 OLI and TIRS data in Florence and Naples city, Italy," European Journal of Remote Sensing, vol. 51, no. 1, pp. 667678, 2018.

[9] A. S. Hope and T. P. McDowell, "The relationship between surface temperature and a spectral vegetation index of a tallgrass prairie: effects of burning and other landscape controls," International Journal of Remote Sensing, vol. 13, no. 15, pp. 2849-2863, 1992.

[10] Y. Julien, J. A. Sobrino, and W. Verhoef, "Changes in land surface temperatures and NDVI values over Europe between 1982 and 1999," Remote Sensing of Environment, vol. 103, no. 1, pp. 43-55, 2006.

[11] R. C. G. Smith and B. J. Choudhury, "On the correlation of indices of vegetation and surface temperature over SouthEastern Australia," International Journal of Remote Sensing, vol. 11, no. 11, pp. 2113-2120, 1990.

[12] Y. Ghobadi, B. Pradhan, H. Z. M. Shafri, and K. Kabiri, "Assessment of spatial relationship between land surface temperature and land use/cover retrieval from multi-temporal remote sensing data in South Karkheh Sub-basin, Iran," Arabian Journal of Geosciences, vol. 8, no. 1, pp. 525-537, 2014.

[13] C. Qu, J. H. Ma, Y. Q. Xia, and T. Fei, "Spatial distribution of land surface temperature retrieved from MODIS data in Shiyang River Basin," Arid Land Geography, vol. 37, pp. 125-133, 2014.

[14] Y. Zhou, T. M. Shi, Y. M. Hu, and M. Liu, "Relationships between land surface temperature and normalized difference vegetation index based on urban land use type," Chinese Journal of Ecology, vol. 30, pp. 1504-1512, 2011.

[15] Z. N. Li, D. Sibo, T. Bohui et al., "Review of methods for land surface temperature derived from thermal infrared remotely sensed data," Journal of Remote Sensing, vol. 20, pp. 899-920, 2016.

[16] D. Stroppiana, M. Antoninetti, and P. A. Brivio, "Seasonality of MODIS LST over Southern Italy and correlation with land cover, topography and solar radiation," European Journal of Remote Sensing, vol. 47, no. 1, pp. 133-152, 2014.

[17] L. J. Wen, P. Wenfu, Y. Huarong, W. Huaiying, D. Lijun, and S. Xue, "An analysis of land surface temperature (LST) and its influencing factors in summer in Western Sichuan Plateau: a case study of Xichang City," Remote Sensing for Land and Resources, vol. 29, no. 2, pp. 207-214, 2017.

[18] S. Bonafoni, "Spectral index utility for summer urban heating analysis," Journal of Applied Remote Sensing, vol. 9, no. 1, Article ID 096030, 2015.

[19] R. C. Estoque, Y. Murayama, and S. W. Myint, "Effects of landscape composition and pattern on land surface temperature: an urban heat island study in the megacities of Southeast Asia," Science of The Total Environment, vol. 577, pp. 349-359, 2017.

[20] M. Fatemi and M. Narangifard, "Monitoring LULC changes and its impact on the LST and NDVI in district 1 of Shiraz city," Arabian Journal of Geosciences, vol. 12, no. 4, p. 127, 2019.

[21] F. Ferrelli, M. A. Huamantinco Cisneros, A. L. Delgado, and M. C. Piccolo, "Spatial and temporal analysis of the LST-
NDVI relationship for the study of land cover changes and their contribution to urban planning in Monte Hermoso, Argentina," Documents d'Anàlisi Geogràfica, vol. 64, no. 1, pp. 25-47, 2018.

[22] Y. Jamei, P. Rajagopalan, and Q. C. Sun, "Time-series dataset on land surface temperature, vegetation, built up areas and other climatic factors in top 20 global cities (2000-2018)," Data in Brief, vol. 23, p. 103803, 2015.

[23] K. Liu, X. Zhang, X. Li, and H. Jiang, "Multiscale analysis of urban thermal characteristics: case study of Shijiazhuang, China," Journal of Applied Remote Sensing, vol. 8, no. 1, Article ID 083649, 2014.

[24] X. Luo and W. Li, "Scale effect analysis of the relationships between urban heat island and impact factors: case study in Chongqing," Journal of Applied Remote Sensing, vol. 8, no. 1, Article ID 084995, 2014.

[25] S. Naeem, C. Cao, M. M. Waqar, C. Wei, and B. K. Acharya, "Vegetation role in controlling the ecoenvironmental conditions for sustainable urban environments: a comparison of Beijing and Islamabad," Journal of Applied Remote Sensing, vol. 12, no. 1, Article ID 016013, 2018.

[26] K. Shigeto, "Relation between vegetation, surface temperature, and surface composition in the Tokyo region during winter," Remote Sensing of Environment, vol. 50, no. 1, pp. 52-60, 1994.

[27] W. Z. Yue, X. J. Hua, and X. L. Hua, "An analysis on ecoenvironmental effect of urban land use based on remote sensing images: a case study of urban thermal environment and NDVI," Acta Ecologica Sinica, vol. 26, pp. 1450-1460, 2006.

[28] H. K. Zhang, B. Huang, M. Zhang, K. Cao, and L. Yu, “A generalization of spatial and temporal fusion methods for remotely sensed surface parameters," International Journal of Remote Sensing, vol. 36, no. 17, pp. 4411-4445, 2015.

[29] J. A. Voogt and T. R. Oke, "Thermal remote sensing of urban climates," Remote Sensing of Environment, vol. 86, no. 3, pp. 370-384, 2003.

[30] S. N. Goward, Y. Xue, and K. P. Czajkowski, "Evaluating land surface moisture conditions from the remotely sensed temperature/vegetation index measurements: an exploration with the simplified simple biosphere model," Remote Sensing of Environment, vol. 79, no. 2-3, pp. 225-242, 2002.

[31] H. Govil, S. Guha, A. Dey, and N. Gill, "Seasonal evaluation of downscaled land surface temperature: a case study in a humid tropical city," Heliyon, vol. 5, no. 6, Article ID e01923, 2019.

[32] H. Govil, S. Guha, P. Diwan, N. Gill, and A. Dey, "Analyzing linear relationships of LST with NDVI and MNDISI using various resolution levels of Landsat 8 OLI and TIRS data," in Data Management, Analytics and Innovation, N. Sharma, A. Chakrabarti, and V. Balas, Eds., vol. 1042, Springer, Advances in Intelligent Systems and Computing, pp. 171-184, Springer, 2020b.

[33] S. Guha, H. Govil, A. Dey, and N. Gill, "A case study on the relationship between land surface temperature and land surface indices in Raipur City, India," Geografisk TidsskriftDanish Journal of Geography, pp. 1-16, 2020a.

[34] S. Guha, H. Govil, N. Gill, and A. Dey, "Analytical study on the relationship between land surface temperature and land use/land cover indices," Annals of GIS, 2020b.

[35] G. Gutman and A. Ignatov, "The derivation of the green vegetation fraction from NOAA/AVHRR data for use in numerical weather prediction models," International Journal of Remote Sensing, vol. 19, no. 8, pp. 1533-1543, 1998.

[36] Q. Weng, D. Lu, and J. Schubring, "Estimation of land surface temperature-vegetation abundance relationship for urban 
heat island studies," Remote Sensing of Environment, vol. 89, no. 4, pp. 467-483, 2004.

[37] B. Hao, M. Ma, S. Li et al., "Land use change and climate variation in the three gorges reservoir catchment from 2000 to 2015 based on the google earth engine," Sensors, vol. 19, no. 9, p. 2118, 2019.

[38] Q. Hassan, C. Bourque, F.-R. Meng, and R. Cox, "A wetness index using terrain-corrected surface temperature and normalized difference vegetation index derived from standard MODIS products: an evaluation of its use in a humid forestdominated region of eastern Canada," Sensors, vol. 7, no. 10, pp. 2028-2048, 2007.

[39] K. Li and Z. Yu, "Comparative and combinative study of urban heat island in Wuhan city with remote sensing and CFD simulation," Sensors, vol. 8, no. 10, pp. 6692-6703, 2008.

[40] H. Liu and Q. Weng, "Scaling effect of fused ASTER-MODIS land surface temperature in an urban environment," Sensors, vol. 18, no. 11, p. 4058, 2018.

[41] P. Mohammad, A. Goswami, and S. Bonafoni, "The impact of the land cover dynamics on surface urban heat island variations in semi-arid cities: a case study in Ahmedabad city, India, using multi-sensor/source data," Sensors, vol. 19, no. 17, p. 3701, 2019.

[42] S. A. Nowicki, R. D. Inman, T. C. Esque, K. E. Nussear, and C. S. Edwards, "Spatially consistent high-resolution land surface temperature mosaics for thermophysical mapping of the mojave desert," Sensors, vol. 19, no. 12, p. 2669, 2019.

[43] H. Qi, F. Huang, and H. Zhai, "Monitoring spatio-temporal changes of terrestrial ecosystem soil water use efficiency in Northeast China using time series remote sensing data," Sensors, vol. 19, no. 6, p. 1481, 2019.

[44] O. Rozenstein, Z. Qin, Y. Derimian, and A. Karnieli, "Derivation of land surface temperature for landsat-8 TIRS using a split window algorithm," Sensors, vol. 14, no. 4, pp. 57685780, 2014.

[45] Y. Shi, Y. Xiang, and Y. Zhang, "Urban design factors influencing surface urban heat island in the high-density city of Guangzhou based on the local climate zone," Sensors, vol. 19, no. 16, p. 3459, 2019.

[46] L. Slawsky, L. Zhou, S. Roy, G. Xia, M. Vuille, and R. Harris, "Observed thermal impacts of wind farms over northern Illinois," Sensors, vol. 15, no. 7, pp. 14981-15005, 2015.

[47] H. Sun, B. Zhou, and H. Liu, "Spatial evaluation of soil moisture (SM), land surface temperature (LST), and LSTderived SM indexes dynamics during SMAPVEX12," Sensors, vol. 19, no. 5, p. 1247, 2019.

[48] J. Zhang and Y. Wang, "Study of the relationships between the spatial extent of surface urban heat islands and urban characteristic factors based on landsat ETM+ data," Sensors, vol. 8, no. 11, pp. 7453-7468, 2008.

[49] S. Guha, H. Govil, and S. Mukherjee, "Dynamic analysis and ecological evaluation of urban heat islands in Raipur city, India," Journal of Applied Remote Sensing, vol. 11, no. 3, Article ID 036020, 2017.

[50] N. Kikon, P. Singh, S. K. Singh, and A. Vyas, "Assessment of urban heat islands (UHI) of Noida City, India using multitemporal satellite data," Sustainable Cities and Society, vol. 22, pp. 19-28, 2016.

[51] D. Kumar and S. Shekhar, "Statistical analysis of land surface temperature-vegetation indexes relationship through thermal remote sensing," Ecotoxicology and Environmental Safety, vol. 121, pp. 39-44, 2015.

[52] A. Mathew, S. Khandelwal, and N. Kaul, "Investigating spatial and seasonal variations of urban heat island effect over Jaipur city and its relationship with vegetation, urbanization and elevation parameters," Sustainable Cities and Society, vol. 35, pp. 157-177, 2017.

[53] A. Mathew, S. Khandelwal, and N. Kaul, "Spatio-temporal variations of surface temperatures of Ahmedabad city and its relationship with vegetation and urbanization parameters as indicators of surface temperatures," Remote Sensing Applications: Society and Environment, vol. 11, pp. 119-139, 2018.

[54] P. Singh, N. Kikon, and P. Verma, "Impact of land use change and urbanization on urban heat island in Lucknow city, Central India. A remote sensing based estimate," Sustainable Cities and Society, vol. 32, pp. 100-114, 2017.

[55] Z. Qin, A. Karnieli, and P. Berliner, "A mono-window algorithm for retrieving land surface temperature from Land$\mathrm{sat}^{\mathrm{TM}}$ data and its application to the Israel-Egypt border region," International Journal of Remote Sensing, vol. 22, no. 18 , pp. 3719-3746, 2001.

[56] S. Guha, H. Govil, and P. Diwan, "Analytical study of seasonal variability in land surface temperature with normalized difference vegetation index, normalized difference water index, normalized difference built-up index, and normalized multiband drought index," Journal of Applied Remote Sensing, vol. 13, no. 2, Article ID 024518, 2019.

[57] S. Guha and H. Govil, "Evaluation of ASTER TIR data-based lithological indices in Malanjkhand copper mines of Madhya Pradesh, India," Applied Earth Science, vol. 129, no. 1, pp. 3-8, 2019.

[58] Y. Ke, J. Im, J. Lee, H. Gong, and Y. Ryu, "Characteristics of Landsat 8 oli-derived NDVI by comparison with multiple satellite sensors and in-situ observations," Remote Sensing of Environment, vol. 164, pp. 298-313, 2015.

[59] T. Purevdorj, R. Tateishi, T. Ishiyama, and Y. Honda, "Relationships between percent vegetation cover and vegetation indices," International Journal of Remote Sensing, vol. 19, no. 18 , pp. 3519-3535, 1998.

[60] C. J. Tucker, "Red and photographic infrared linear combinations for monitoring vegetation," Remote Sensing of Environment, vol. 8, no. 2, pp. 127-150, 1979. 